\title{
Effect of intestinal resection on human small bowel motility
}

\author{
T Schmidt, A Pfeiffer, N Hackelsberger, R Widmer, C Meisel, H Kaess
}

\begin{abstract}
Background-Few data are available on adaptive changes of human small bowel motility after intestinal resection.

Aim-To characterise jejunal motility after extensive and limited distal intestinal resection.

Methods-Seven patients with a short bowel syndrome after total ileal and partial jejunal resection (residual jejunal segments between 60 and $100 \mathrm{~cm}$ ) and six patients with limited distal ileal resection (resected segment between 30 and $70 \mathrm{~cm}$ ) underwent ambulatory 24 hour jejunal manometry 15 (6-24) months after the operation. Normal values were obtained from 50 healthy subjects. Fasting motility and the motor response to a $600 \mathrm{kcal}$ solid meal were analysed visually and by a computer program.
\end{abstract}

Results-Limited ileal resection did not result in changed jejunal motility. After extensive distal resection, patients had a significantly shorter migrating motor complex (MMC) cycle and a significantly shorter duration of the postprandial motor response compared with controls $(p<0.005)$. Intestinal resection had no influence on jejunal contraction frequency and amplitude and did not lead to any abnormal motor pattern.

Conclusion-Extensive distal resection of the small intestine produces distinct abnormalities of fasting and postprandial motility in the intestinal remnant. The shortening of digestive motility and the increased frequency of MMC cycling could contribute to malabsorption and diarrhoea in the short bowel syndrome. (Gut 1996; 38: 859-863)

Keywords: small bowel syndrome, small bowel motility, small bowel manometry.

Department of Gastroenterology and Hepatology, Städtisches Krankenhaus MünchenBogenhausen, Akademisches Lehrkrankenhaus, Munich, Germany T Schmidt

A Pfeiffer

N Hackelsberger

$\mathrm{R}$ Widmer

C Meisel

$\mathrm{H}$ Kaess

Correspondence to Dr T Schmidt, Department of Gastroenterology, Hospital Bogenhausen Englschalkingerstrasse 77 D-81925 Munich, Germany. Accepted for publication 29 December 1995 intestinal remnant undergoes complex adaptive changes in an attempt to restore homeostasis. ${ }^{1-3}$ While research had largely been
After resection of a part of the small bowel, the

TABLE I Clinical features of patients with short bowel syndrome

^Body mass index $\left(\mathrm{kg} / \mathrm{m}^{2}\right)$. focused on mucosal adaptation, little is known about changes in motility, though it is assumed to play an important part in the absorption of nutrients and the aboral transit of luminal contents in the gut. ${ }^{4}$ Animal studies after intestinal resection have yielded conflicting results. ${ }^{5-7}$ In humans with a short bowel syndrome, changes in the length and composition of the cyclical fasting pattern, known as the migrating motor complex (MMC), have been reported ${ }^{8}{ }^{9}$ using stationary manometry for six hours. The motor response to a solid meal in these patients has not been studied. Changes could be expected, particularly during postprandial motility, as under physiological conditions, nutrients in the ileum are well known to exert an important inhibitory influence on jejunal motor function. ${ }^{10-14}$ As it has become increasingly recognised that human small bowel motility is highly variable, ${ }^{15-17}$ some authors have claimed that longterm recordings are necessary to obtain reliable data on the MMC. 1819

The aim of this study was to characterise the effect of intestinal resection on human jejunal motility by 24 hour manometry. To elucidate the role of the length of resection, patients after both extensive and limited distal resection were investigated.

\section{Methods}

\section{Patients and controls}

Two groups of patients were investigated 15 (6-24) months after intestinal resection. The length of the intestinal remnant was assessed both at operation and radiologically by the enteroclysis technique in all patients.

The first group, seven patients (three males, four females) aged 74 (65-81) years, had a short bowel syndrome after extensive distal small intestinal resection. Table I shows their clinical data. In all short bowel patients, an intact stomach and an intact duodenum were present and the jejunal remnant, ranging from 30 to $100 \mathrm{~cm}$ in length, had been anastomosed to the colon. All short bowel patients were in a stable nutritional, fluid, and electrolyte state

\begin{tabular}{|c|c|c|c|c|c|c|c|}
\hline & Age & Sex & Cause for resection & $\begin{array}{l}\text { Small bowel } \\
\text { remnant }\end{array}$ & Current bowel anatomy & $\begin{array}{l}\text { Stool weight } \\
\text { (g/day) }\end{array}$ & $B M I^{\star}$ \\
\hline A & 72 & $\mathbf{F}$ & Mesenteric artery occlusion & $30 \mathrm{~cm}$ Jejunum & Jejunotransverse colostomy & 2000 & $15 \cdot 6$ \\
\hline B & 80 & $\mathrm{~F}$ & Radiation enteritis & $30 \mathrm{~cm}$ Jejunum & Jejunotransverse colostomy & 2900 & $13 \cdot 3$ \\
\hline C & 73 & $\mathbf{M}$ & Mesenteric volvolus & $40 \mathrm{~cm}$ Jejunum & Jejunodescending colostomy & 1950 & $14 \cdot 1$ \\
\hline D & 75 & $\mathbf{M}$ & Mesenteric artery occlusion & $50 \mathrm{~cm}$ Jejunum & Jejunoascending colostomy & 1800 & $19 \cdot 3$ \\
\hline E & 81 & $\mathrm{~F}$ & Mesenteric artery occlusion & $60 \mathrm{~cm}$ Jejunum & Jejunotransverse colostomy & 1520 & $16 \cdot 2$ \\
\hline $\mathrm{F}$ & 72 & $\mathbf{M}$ & Mesenteric vein thrombosis & $100 \mathrm{~cm}$ Jejunum & Jejunoascending colostomy & 1200 & $20 \cdot 7$ \\
\hline G & 65 & $\mathbf{F}$ & Perforated caecal cancer & $100 \mathrm{~cm}$ Jejunum & Jejunotransverse colostomy & 1600 & $15 \cdot 4$ \\
\hline
\end{tabular}


and were already receiving oral alimentation at the time of investigation. Two patients ( $A$ and $B$ in Table I) received additional parenteral nutrition, which was discontinued during the motility recordings.

The second group, six patients (two males, four females) aged 48 (32-78) years had undergone resection of $40(30-60) \mathrm{cm}$ of the terminal ileum and the caecum with ileoascending colonostomy. Resection had been performed because of adhesions $(n=3)$ and Crohn's disease $(n=3)$. All patients of this group were free of gastrointestinal symptoms at the time of investigation and their daily stool weight and body mass index were normal. Patients with Crohn's disease had no evidence of current active disease as assessed clinically, radiologically, and biochemically.

The control group consisted of 50 healthy volunteers (28 males, 22 females) aged 26 (19-46) years free of gastrointestinal complaints who had been studied according to the same protocol. No control subject had undergone previous abdominal surgery, except uncomplicated appendicectomy. Neither the volunteers nor the patients were taking any medication known to affect gastrointestinal motility.

The study protocol, which was in accordance with the Declaration of Helsinki had been approved by the local ethics committee. Written informed consent was obtained from each subject.

\section{Study protocol}

The protocol was designed to study both diurnal and nocturnal fasting motility and the response to a standardised solid meal. After an overnight fast, intubation of the small intestine was performed transnasally in the morning of day 1. Using fluoroscopic guidance with a freeze frame facility, the catheter was placed with its proximal sensor at the ligament of Treitz as described previously. ${ }^{20}$ Recordings started between 11 and 12 am and were continued for 24 hours under ambulatory conditions without any restriction of physical activity. Food intake was standardised and consisted of only one meal (bread, cheese, sausages, and fruit yoghurt, $600 \mathrm{kcal}, 40 \%$ proteins, $40 \%$ carbohydrates, $20 \%$ fat), which was ingested at $6 \mathrm{pm}$ on day 1 . Tap water was permitted ad libitum. Bed rest was scheduled from $11 \mathrm{pm}$ on day 1 to 6 am on day 2 . Day 2 was spent fasting until the recordings were terminated after a total recording period of 24 hours. Subjects kept a diary in which their activities were recorded.

\section{Digital recording system}

Motility was recorded with fine (OD $2.3 \mathrm{~mm}$ ) flexible catheters incorporating two piezoresistive miniature strain-gauge transducers (Keller AG, Winterthur, Switzerland) spaced at $15 \mathrm{~cm}$ intervals at their distal parts. Calibration of the catheter was performed in a water bath at $37^{\circ} \mathrm{C}$ for 30 minutes before each measurement. Data were stored on a $2 \mathrm{MB}$ portable data logger
(PMT Megalogger, Göttingen; Germany). Pressure was sampled at a rate of $3 \mathrm{~Hz}$, which has been reported to detect phasic pressure waves from the upper small intestine without significant reduction of the signal amplitude. ${ }^{21}$

\section{Data analysis}

Data were downloaded to an IBM compatible personal computer (486 DX 2, ESCOM Computers, Munich, Germany) without any reduction. Both visual and computer aided analyses $^{22}$ were undertaken. All steps of visual analysis - that is, recognition of motility phases and identification of special motor patterns as described below - were performed on separate occasions by two observers without prior knowledge whether patient or control recordings were studied.

According to the subject's protocol, each recording period was subdivided into a diurnal and a nocturnal period (usually from $11 \mathrm{pm}$ to 6 am) with reference to the waking (W) or sleeping (S) state of the subject and marked by mouse operation as regions of interest on the monitor. In a similar way, fasting motility, its constituent phases, and postprandial activity were marked and stored on separate computer files. Fasting motility was subdivided into three phases. ${ }^{23}$ Phase I was defined as motor quiescence. ${ }^{23}$ To facilitate comparison of our MMC data with previous motility recordings in the human short bowel syndrome, ${ }^{8}$ phase II (irregular contractile activity) was defined to start when the contractile activity at any recording site exceeded more than two phasic contractions per 10 minutes. ${ }^{24}$ Phase III was defined as a rhythmic series of uninterrupted contractions at a maximal rate of $10-12$ per minute and a duration of more than two minutes followed by motor quiescence. ${ }^{23}$ Aboral migration velocity phase III was determined visually by dividing the length of the recording segment $(15 \mathrm{~cm})$ by the time taken for the onset of phase III to transverse this distance. ${ }^{23}$ MMC cycle length was defined as the time period between the end of successive phase III activities at the distal recording site. Incomplete MMC cycles were excluded from data analysis. Postprandial motility was defined as the time period from the beginning of the meal to either the return of phase III or phase I. 2425

In all recordings, phase II, III, and postprandial activity underwent quantitative automated analysis by a computer program designed for the rejection of artefacts and the recognition of phasic small bowel contractile events that has been developed and validated in our laboratory. ${ }^{22}$ Briefly, phasic pressure events exceeding an amplitude of $9.7 \mathrm{~mm} \mathrm{Hg}$, a duration of $2.8 \mathrm{~s}$, and an area under the curve of $18.4 \mathrm{~s} \times \mathrm{mm} \mathrm{Hg}$ without simultaneous events in other recording channels were considered by the algorithm as a real contraction. From the data files of recognised contractions, the mean values for contraction frequency $\left(\mathrm{min}^{-1}\right)$ and contraction amplitude $(\mathrm{mm} \mathrm{Hg})$ were calculated.

Finally, as described in a previous case report, ${ }^{9}$ phase II and postprandial motility 
TABLE II Duration and composition of MMC cycles recorded during the waking (W) and sleeping (S) state in healthy controls, patients with short bowel syndrome, and patients after partial ileal resection. Values are means (SEM), t test

\begin{tabular}{lccccc}
\hline & $\begin{array}{l}\text { Controls } \\
(n=50)\end{array}$ & & $\begin{array}{l}\text { Short bowels } \\
(n=7)\end{array}$ & $\begin{array}{l}\text { Ileal resections } \\
(n=6)\end{array}$ \\
\hline$M M C$ (W) & & & & & \\
Cycle length (min) & $101(5)$ & $\mathrm{p}<0.005$ & $51(4)$ & $\mathrm{p}<0.01$ & $99(5)$ \\
Phase I (min) & $16(2)$ & $\mathrm{p}<0.05$ & $8(2)$ & $\mathrm{p}<0.05$ & $20(2)$ \\
Phase II (min) & $81(5)$ & $\mathrm{p}<0.005$ & $38(5)$ & $\mathrm{p}<0.01$ & $75(7)$ \\
Phase III (min) & $4.4(0.2)$ & & $4.7(0.4)$ & & $4.3(0.3)$ \\
$M M C$ (S) & & & & & \\
Cycle length (min) & $85(3)$ & $\mathrm{p}<0.005$ & $43(5)$ & $\mathrm{p}<0.01$ & $90(5)$ \\
Phase I (min) & $46(3)$ & $\mathrm{p}<0.01$ & $27(4)$ & $\mathrm{p}<0.05$ & $54(4)$ \\
Phase II (min) & $34(3)$ & $\mathrm{p}<0.005$ & $10(1)$ & $\mathrm{p}<0.01$ & $30(4)$ \\
Phase III (min) & $5.4(0.2)$ & & $6.0(0.3)$ & & $5.8(0.5)$ \\
\hline
\end{tabular}

TABLE III Parameters of phase II activity recorded in the waking (W) and sleeping (S) state in healthy controls, patients with the short bowel syndrome, and patients after partial ileal resection. Values are means (SEM), t test

\begin{tabular}{|c|c|c|c|}
\hline & $\begin{array}{l}\text { Controls } \\
(n=50)\end{array}$ & $\begin{array}{l}\text { Short bowels } \\
(n=7)\end{array}$ & $\begin{array}{l}\text { Ileal resections } \\
(n=6)\end{array}$ \\
\hline $\begin{array}{l}\text { Phase II }(W) \\
\text { Contraction frequency }\left(\mathrm{min}^{-1}\right) \\
\text { Contraction amplitude }\left(\mathrm{mm} \mathrm{Hg}^{\mathrm{H}}\right)\end{array}$ & $\begin{array}{r}2 \cdot 0(0 \cdot 1) \\
23 \cdot 0(0.5)\end{array}$ & $\begin{array}{r}2 \cdot 1(0 \cdot 3) \\
24 \cdot 7(0.9)\end{array}$ & $\begin{array}{r}2 \cdot 1(0 \cdot 2) \\
24 \cdot 0(0 \cdot 7)\end{array}$ \\
\hline $\begin{array}{l}\text { Phase II }(S) \\
\text { Contraction frequency }\left(\mathrm{min}^{-1}\right) \\
\text { Contraction amplitude }\left(\mathrm{mm} \mathrm{Hg}^{\mathrm{H}}\right)\end{array}$ & $\begin{array}{r}1 \cdot 3(0 \cdot 1) \\
24 \cdot 1(1 \cdot 0)\end{array}$ & $\begin{array}{r}1.0(0.3) \\
23.2(0.8)\end{array}$ & $\begin{array}{r}1 \cdot 1(0 \cdot 2) \\
24 \cdot 0(0 \cdot 7)\end{array}$ \\
\hline
\end{tabular}

underwent visual analysis for two special motor patterns, discrete clustered contractions (DCCs), and prolonged contractions. A DCC was defined as a rhythmic series of 3-10 phasic contractions occurring at a frequency of 10-12 per minute ${ }^{26}$ preceded and followed by at least 30 seconds of absent motor activity and showing aboral migration through the whole recording segment of $15 \mathrm{~cm}$. The overall incidence of DCCs (per h) was determined. A prolonged contraction was defined as a single or double pressure wave of an amplitude $>20 \mathrm{~mm} \mathrm{Hg}$ and a duration $>20 \mathrm{s.}^{27}$ In addition, it was determined, whether DCCs and prolonged contractions were propagated in an oral or aboral direction or appeared simultaneously at both recording sites. To avoid rejecting simultaneous events as artefacts, only unprocessed signals were used for this step of analysis.

\section{Statistical analysis}

Results of visual and computerised analysis were entered into a preprogrammed database (Paradox 1.0; Borland International, Scotts Valley, CA, USA) for further statistical evaluation. According to a previous study on the short bowel syndrome in humans, ${ }^{8}$ the replicate observations within a subject over the recording period (for example the duration of several phase II(W) episodes) were first averaged to obtain a mean value for each parameter (a

TABLE IV Parameters of phase III motility in patients with the short bowel syndrome, healthy controls, and patients after partial ileal resection. Values are means (SEM), t test

\begin{tabular}{|c|c|c|c|}
\hline & $\begin{array}{l}\text { Controls } \\
(n=50)\end{array}$ & $\begin{array}{l}\text { Short bowels } \\
(n=7)\end{array}$ & $\begin{array}{l}\text { Ileal resections } \\
(n=6)\end{array}$ \\
\hline $\begin{array}{l}\text { Phase III }(W) \\
\text { Contraction frequency }\left(\mathrm{min}^{-1}\right) \\
\text { Contraction amplitude }(\mathrm{mm} \mathrm{Hg}) \\
\text { Aboral migration velocity }(\mathrm{cm} / \mathrm{min})\end{array}$ & $\begin{array}{l}10.3(0.1) \\
28.8(0.8) \\
11.0(1.2)\end{array}$ & $\begin{array}{r}10 \cdot 2(0 \cdot 1) \\
29 \cdot 2(1 \cdot 0) \\
9 \cdot 3(1 \cdot 7)\end{array}$ & $\begin{array}{l}10 \cdot 3(0 \cdot 2) \\
28 \cdot 0(0 \cdot 7) \\
10 \cdot 0(1 \cdot 1)\end{array}$ \\
\hline $\begin{array}{l}\text { Phase III }(S) \\
\text { Contraction frequency }\left(\mathrm{min}^{-1}\right) \\
\text { Contraction amplitude }(\mathrm{mm} \mathrm{Hg}) \\
\text { Aboral migration velocity }(\mathrm{cm} / \mathrm{min})\end{array}$ & $\begin{array}{r}10 \cdot 2(0 \cdot 1) \\
27 \cdot 5(0 \cdot 8) \\
8 \cdot 0(0 \cdot 6)\end{array}$ & $\begin{array}{r}10 \cdot 1(0 \cdot 2) \\
28 \cdot 0(0.9) \\
7 \cdot 1(0.9)\end{array}$ & $\begin{array}{r}10.3(0.5) \\
26.8(0.7) \\
7.5(0.7)\end{array}$ \\
\hline
\end{tabular}

mean duration of phase II(W) for that person). Comparisons were then based on the independent two sample $t$ test and $t$ test for paired observations, when appropriate. Corrections for multiple significance tests were made by the Bonferroni method. ${ }^{28}$ All results are expressed mean (SEM). Differences were considered significant if $\mathrm{p}$ was less than 0.05 after correction.

\section{Results}

\section{Fasting motility}

$M M C$ cycles - In all patients and all controls, fasting motility in the waking and sleeping state was characterised by recurrent MMC cycling. Table II summarises the characteristics. During wakefulness and during sleep, the patients with the short bowel syndrome showed significantly shorter MMC cycle length compared with both controls $(p<0.005)$, and compared with patients with ileal resection $(p<0.01)$. The shortening of MMC cycles in short bowel patients was mainly due to a shorter phase II (W/S), but also phase I (W/S) proved to be significantly shorter. In the patients with ileal resection, the duration and composition of MMC (W/S) cycles was not different from the control group. The normal variation of the MMC with the wake-sleep-cycle, ${ }^{29}$ that is a shorter cycle length with a predominance of phase I during sleep, and a predominance of phase II during wakefulness was present in both patient groups.

Phase II features - Table III summarises the parameters of phase II activity. Neither the contraction frequency nor the contraction amplitude showed differences between the two patient groups and healthy subjects. A significant $(p<0.01)$ decrease in contraction frequency during sleep was seen in patients and controls.

Phase III features - Table IV summarises the parameters characterising phase III activity. The contraction frequency, the contraction amplitude, and the aboral migration velocity of phase III did not differ between patients and controls. In all recordings, an aboral migration of phase III was seen. In patients and controls, phase III migration velocity slowed down during sleep $(\mathrm{p}<0.05)$.

\section{Postprandial motility}

The intake of the standardised evening meal induced a postprandial motor response of irregular contractile activity in all patients and controls. Table $\mathrm{V}$ shows the data on postprandial motility. The duration of postprandial motility was significantly shorter in patients with the short bowel syndrome compared with controls $(p<0.005)$ and with patients with ileal resection $(p<0 \cdot 01)$. In patients with ileal resection, the duration of postprandial motility tended to be shorter than in controls $(p=0.05$ without correction). The contraction frequency and the contraction amplitude were not different between patients and controls. 
TABLE V Parameters of postprandial motility in healthy controls, patients with the short bowel syndrome, and patients after partial ileal resection. Values are means (SEM), t test

\begin{tabular}{|c|c|c|c|c|c|}
\hline & $\begin{array}{l}\text { Controls } \\
(n=50)\end{array}$ & & $\begin{array}{l}\text { Short bowels } \\
(n=7)\end{array}$ & & $\begin{array}{l}\text { Ileal resections } \\
(n=6)\end{array}$ \\
\hline $\begin{array}{l}\text { Duration of postprandial motility (min) } \\
\text { Contraction frequency }\left(\mathrm{min}^{-1}\right) \\
\text { Contraction amplitude }\left(\mathrm{mm} \mathrm{Hg}^{\mathrm{H}}\right)\end{array}$ & $\begin{array}{l}263(13) \\
3 \cdot 1(0 \cdot 2) \\
23 \cdot 7(0 \cdot 5)\end{array}$ & $\mathrm{p}<0.005$ & $\begin{array}{r}126(14) \\
2 \cdot 7(0 \cdot 5) \\
24 \cdot 5(0 \cdot 9)\end{array}$ & $\mathrm{p}<0.01$ & $\begin{array}{l}218(12) \\
3 \cdot 0(0 \cdot 5) \\
24 \cdot 0(0 \cdot 7)\end{array}$ \\
\hline
\end{tabular}

Special motor patterns

During phase II and postprandial motility, DCCs were identified in each recording. Their frequency during phase II was $7 \cdot 0(0.6)$ per $h$ in controls and did not differ significantly from that in short bowel patients $(6 \cdot 1(0 \cdot 8)$ per $\mathrm{h})$ and ileal resection patients $(6.8(0.5)$ per $h)$. During postprandial motility, an increase in DCCs $(p<0.05)$ compared with phase II was seen in controls $(10.4(0.8)$ per $\mathrm{h})$, short bowel $(11.2(1.1)$ per $h)$, and ileal resection patients $(9 \cdot 7(1 \cdot 2)$ per $\mathrm{h})$, but no differences between the groups were present. In controls and patients, no simultaneous or retrograde DCCs were detected. Prolonged contractions were not detected in any recording.

\section{Discussion}

In this study, 24 hour jejunal motility was recorded in patients with extensive and limited distal resection of the small intestine and compared with results obtained in a large groups of healthy subjects. Two main findings emerged: limited ileal resection including resection of the ileocaecal valve does not result in detectable manometric changes of jejunal motility. In contrast, extensive distal resection of the small intestine modifies fasting and postprandial motility in the intestinal remnant and is characterised by a pronounced shortening of the MMC cycle length and the duration of the so called fed state.

Our data in patients after ileal resection are in agreement with the finding of an unchanged motor activity in the remaining jejunum after ileal resection in the rat reported by Wittmann et al. 56 The recordings in the short bowel syndrome, obtained for the first time over a 24 hour period, confirm and extend previous findings made with stationary short-term manometry. Remington and coworkers ${ }^{8}$ who studied six patients with a short bowel syndrome for six hours found a reduction of the MMC cycle length from 101 minutes in controls to 71 minutes in patients. A similar finding was recently made in a single case report. ${ }^{9}$ The reduction of the cycle length in Remington's study $^{8}$ was due to a reduced duration of phase II. Our prolonged recordings show a more pronounced shortening of the MMC cycle length caused by a shorter duration of both phase I and phase II, which remained fairly unchanged in their relative contribution to the MMC cycle. Furthermore, the shortening of the cycle and its constituent phases was shown to be a constant finding over the 24 hour period and to persist during wakefulness and sleep. The physiological diurnal variation ${ }^{29}$ of fasting motility with the wake-sleep cycle (mainly characterised by a predominance of phase II during wakefulness, a predominance of phase I, and a reduced contraction frequency of phase II during sleep), which is believed to be centrally mediated, ${ }^{30}$ is preserved in the short bowel syndrome. As Husebye et $a l^{31}$ have demonstrated that aging does not modify the human MMC, the age difference between controls and short bowel patients should not account for our findings. We cannot exclude, however, that differences in the intestinal microflora, which is a luminal control factor of MMC cycling, ${ }^{32-34}$ play a causal part.

Recently, Quigley et $a l^{7}$ reported that in dogs that were studied for three months after 25,50 , and $75 \%$ distal resection of the small bowel, fasting and postprandial motility in the intestinal remnant is dominated by discoordinate clustered activity, a finding that contrasts with normal clustered activity in our patients. This animal study, however, seems to reflect the very early postoperative changes of motility, and with further adaptation six months after resection, the clustered activity in dogs has normalised. ${ }^{35}$ It must be emphasised that none of our patients was investigated earlier than six months after the operation.

With regard to postprandial motility, the effect of solid meal has, to our knowledge, not been studied by manometry in the short bowel syndrome. Remington et $a l^{8}$ used a liquid $400 \mathrm{ml}$ meal of a defined formula diet after which the duration of postprandial motility was not different between patients and controls. After a solid meal of $50 \%$ more calories in our study, short bowel patients had a considerably shorter postprandial motor response, which seemed to be normal in terms of contraction frequency and contraction amplitude. It could be assumed that a more rapid gastric emptying accounts for this finding, ${ }^{36}$ however, gastric emptying of solids is normal in short bowel patients with a preserved colon ${ }^{37}$ as in our patient group. At present, the underlying mechanism why phase III reappears so early after the meal and cycles so frequently remains unknown. Our data suggest that the length of the small intestine after distal resection exerts a regulatory function on the duration of postprandial motility and on the frequency of MMC cycling.

Finally, could these changes in motility have functional consequences in the short bowel syndrome? Fasting motility returns early in the intestinal remnant. Absorption during any phase of fasting motility has been shown to be much less effective than during the digestive motor state. ${ }^{38}$ Furthermore, transit through the small bowel is well known to be most rapid during phase III $^{39}$ which, together with its secretory component, ${ }^{40}$ propels all luminal contents aborally ahead of the activity front. ${ }^{41}$ 
Therefore, it cannot be excluded that the early postprandial return and the frequent recurrence of phase III lead to an increased loss of calories into the colon and thus contribute to malabsorption and diarrhoea in the short bowel syndrome. Whether therapeutic agents that prolong digestive motility and reduce the frequency of MMC cycling, as we have shown for the antimuscarinic compound trospium chloride ${ }^{20}$ in healthy subjects, can exert a beneficial effect in patients with a short bowel remains to be elucidated.

Part of this work was presented at the 14th International Symposium on Gastrointestinal Motility, Muskoka, Ontario, Canada, 29 August-3 September 1993, and has been published in abstract form ( $\mathcal{F}$ Gastrointest Motil 1993; 5: 216).

1 Williamson RCN, Chir M. Intestinal adaptation-structure, functional and cytokinetic changes. $N$ Engl f Med 1978;

2 Williamson RCN, Chir M. Intestinal adaptation Mechanisms of control. N Engl f Med 1978; 298: 1444-50.

3 Weser E, Fletcher JT, Urban E. Short bowel syndrome Gastroenterology 1979; 77: 572-9.

4 Sarna SK, Otterson MF. Motility disorders. Small intestinal physiology and pathophysiology. Gastroenterol Clin North Am 1989; 18: 375-404.

5 Wittmann T, Crenner F, Pousse A, Grenier JF. Changes in motility after jejunal and ileal resection. Electromyographic motility after jejunal and ileal resection. El

6 Wittmann T, Crenner F, Koenig M, Grenier JF. Adaptive changes in postprandial motility after intestinal resection and bypass. Electromyographic study in rats. Dig Dis $\mathrm{Sc}$ 1988; 33: 1370-6.

7 Quigley EMM, Thompson JS. The motor response to intestinal resection: motor activity in the canine smal intestine following distal resection. Gastroenterology 1993 105: 791-8.

8 Remington M, Malagelada JR, Zinsmeister A, Fleming RC. Abnormalities in gastrointestinal motor activity in patients with short bowels: effect of a synthetic opiate. Gastroenterology 1983; 85: 629-36.

9 Pigot F, Messing B, Chaussade S, Pfeiffer A, Pouliquen X, Jian $R$. Severe short bowel syndrome with a surgically Jian R. Severe short bowel syndrome with a surgically
reversed small bowel segment. Dig Dis Sci 1990; 35: reversed $137-44$.

10 Spiller RC, Trotman IF, Higgins BE, Ghatei MA, Grimble GK, Lee YC, et al. The ileal brake - inhibition of jejunal motility after ileal fat perfusion in man. Gut 1984; 25 365-74.

11 Read NW, McFarlane A, Kinsman RI, Bates TE, Blackhall NW, Farrar GB. Effect of infusion of nutrient solutions into the ileum on gastrointestinal transit and plasma levels of neurotensin and enteroglucagon. Gastroenterology 1984; 86: $274-80$.

12 Spiller RC, Trotman IF, Silk DBA, Lee Yc, Ghatei MA, Bloom SR. Control of jejunal motility by ileal contents Bloom SR. Control of jejunal motility by ileal contents

13 Holgate AM, Read NW. Effect of ileal infusion of intralipid on gastrointestinal transit, ileal flow rate, and carbohydrate absorption in humans after ingestion of a liquid meal. Gastroenterology 1985; 88: 1005-11.

14 Spiller RC, Trotman IF, Adrian TE, Bloom SR, Misiewicz JJ, Silk DBA. Further characterization of the 'ileal brake reflex in man - effect of ileal infusion of partial digests of fat, protein, and starch on jejunal motility and release of neurotensin, enteroglucagon, and peptide YY. Gut 1988 29: 1042-51.

15 Kerlin P, Phillips SF. Variability of motility of the ileum and jejunum in healthy man. Gastroenterology 1982; 82: 694-700.

16 Kellow JE, Borody TJ, Phillips SF, Tucker RL, Haddad AC. Human interdigestive motility: variations in patterns from esophagus to colon. Gastroenterology 1986; 01: 386-95.

17 Dooley CP, Di Lorenzo C, Valenzuela JE. Variability of the migrating motor complex in humans. Dig Dis Sci 1992 37: 723-8.

18 Quigley EMM. Intestinal manometry - technical advances, clinical limitations. Dig Dis Sci 1992; 37: 10-3.

19 Husebye E. Should interdigestive motility of small intestine be recorded by long-term ambulatory or short-term stabe recorded by long-term ambulatory or shor

20 Schmidt T, Widmer R, Pfeiffer A, Kaess H. Effect of the quarternary ammonium compound trospium chloride on quarternary ammonium compound trospium chloride on 24-33.

21 Lindberg G, Iwarzon M, Stal P, Seensalu R. Digital ambulatory monitoring of small-bowel motility. Scand $\mathcal{F}$ Gastroenterol 1990; 25: 216-24.

22 Widmer R, Schmidt T, Pfeiffer A, Kaess H. Computerized analysis of ambulatory long-term jejunal motility. Scand $\mathfrak{J}$ Gastroenterol 1994; 29: 1076-82.

23 Vantrappen G, Janssens J, Hellemans J, Ghoos Y. The interdigestive motor complex of normal subjects and patients with bacterial overgrowth of the small intestine. patients with bacterial overgrowt

24 Hellström PM, Husebye E, Kraglund K. Methodology for motility studies in the small intestine: a Scandinavian conmotility studies in the small intestine: a Scan
sensus. Eur $\mathcal{F}$ Surg 1991; suppl 564: 51-62.

25 Husebye E, Skar A, Aalen O, Osnes M. Digital ambulatory manometry of the small intestine in healthy adults. Dig Dis Sci 1990; 35: 1057-67.

26 Summers RW, Anuras S, Green J. Jejunal manometry patterns in health, partial intestinal obstruction, and pseudoobstruction. Gastroenterology 1983; 85: 1290-300.

27 Camilleri $M$. Jejunal manometry in distal subacute mechanical obstruction: significance of prolonged simultaneous contractions. Gut 1989; 30: 468-75.

28 Bland MJ, Altmann DG. Multiple significance tests: the Bonferroni method. BMF 1995; 310: 170 .

29 Gill RC, Kellow JE, Wingate DL. The migrating motor complex at home [Abstract]. Gastroenterology 1987; 92: compl 1405 .

30 Kellow JE, Eckersly GM, Jones M. Enteric and central contributions to intestinal dysmotility in irritable bowel syndrome. Dig Dis Sci 1992; 37: 168-74.

31 Husebye E, Engedal $\mathrm{K}$. The patterns of motility are maintained in the human small intestine throughout the process of aging. Scand f Gastroenterol 1992; 27: 397-404

32 Caenepeel PH, Janssens J, Vantrappen G, Eyssen H, Coremans G. Interdigestive myoelectric complex in germfree rats. Dig Dis Sci 1989; 34: 1180-4.

33 Husebye E, Hellström PM, Midtvedt T. Introduction of the conventional microbial flora to germfree rats increases the frequency of migrating myoelectric complexes. 7 Gastrointest Motil 1992; 4: 39-45.

34 Husebye E, Hellström PM, Midtvedt I. Intestinal microflora stimulates myoelectric activity of rat smal intestine by promoting cyclic initiation and aboral propagation of migrating myoelectric complex. Dig Dis $\mathrm{Sc}$ 1994; 39: 946-56.

35 Quigley EMM, Thompson JS, Thomas E. Motor adaptation following extensive resection of the small intestine. Gastroenterology 1995; 108: A673.

36 Madsen JL, Dahl K. Human migrating myoelectric complex in relation to gastrointestinal transit of a meal. Gut 1990 ; 31: $1003-6$

37 Nightingale JMD, Kamm MA, van der Sijp JRM, Morris GP, Walker ER, Mather SJ, et al. Disturbed gastric emptying in the short bowel syndrome. Evidence for a colonic tying in the short bowel syndrom

38 Sarr MG, Kelly KA, Phillips SF. Canine jejunal absorption and transit during interdigestive and digestive moto states. Am f Physiol 1980; 239: G167-72.

39 Sarr MG, Kelley KA. Patterns of movement of liquids and solids through canine jejunum. Am f Physiol 1980; 239 G497-503

40 Vantrappen GR, Peeters TL, Janssens J. The secretory component of the interdigestive migrating motor complex in man. Scand $\mathcal{F}$ Gastroenterol 1979; 14: 663-7.

41 Scheemann M, Ehrlein HJ. Mechanical characteristics of phase II and phase III of the interdigestive migrating motor complex in dogs. Gastroenterology 1986; 91: 117-23. 